Publicity, news content, and cultural debate

The changing coverage of blockbuster movies in cultural journalism

Kristensen, Nete Nørgaard; From, Unni

Published in:

Communication, Culture \& Critique

DOI:

$10.1111 /$ cccr. 12094

Publication date:

2015

Document version

Other version

Citation for published version (APA):

Kristensen, N. N., \& From, U. (2015). Publicity, news content, and cultural debate: The changing coverage of blockbuster movies in cultural journalism. Communication, Culture \& Critique, 8(3), 484-501.

https://doi.org/10.1111/cccr.12094 


\title{
Publicity, News Content, and Cultural Debate: The Changing Coverage of Blockbuster Movies in Cultural Journalism
}

\author{
Nete N. Kristensen ${ }^{1} \&$ Unni From ${ }^{2}$ \\ 1 Department of Media, Cognition, and Communication, University of Copenhagen, Copenhagen S 2300, \\ Denmark \\ 2 Department of Aesthetics and Communication, Aarhus University, Aarhus C 8000, Denmark,
}

This article shows that blockbuster movies are predestined to receive media coverage not only because they are increasingly professionally promoted but also because they carry both "publicist" and media commercial news value. e promotional culture surrounding the blockbuster movie event, including the attention devoted to celebrity actors and directors, attracts media audiences, while the movie itself may stimulate sociocultural debate on $\mathrm{lm}$ esthetics, art, celebrity culture, and the cultural industries. Taking our point of departure in mediatization theory, we analyze the interwoven communicative forms of the lm industry and the printed press. We exemplify our arguments with the coverage in Danish newspapers of 3 blockbusters, representing different points in time in the more recent history of lm and news media.

Keywords: Blockbusters, Celebrities, Cultural Journalism, Film Industry, Mediatization, Public Relations (PR), Press Coverage.

doi:10.1111/cccr.12094

When talking pictures were introduced in Denmark in the 1930s, national and international movies, film directors, and stars also soon became important subjects on the newspapers' cultural pages (Kristensen, 2010; Kristensen \& From, 2011). Since then, the often extensive press coverage of, for example, blockbuster movies combined with the increasing personalization and sensationalization (Gripsrud, 2000) of the coverage of art and culture has been interpreted as a transformation from critical, cultural reflection to publicity-driven journalism, entertainment, and celebrity gossip; in other words, it is viewed as a decline in arts and cultural journalism (e.g., Lund, 2005). However, these arguments, voiced both by scholars and in the public debate, focus first and foremost on the commercial motivations of the movie industry and of the media and suggest that media commercial and publicist objectives are almost mutually exclusive. Furthermore, the critical arguments often lack qualitative and historical analytical grounding. These are the motivating reasons behind this article, 
which examines the press coverage of a contested film category, the blockbuster, within the similarly contested framework of cultural journalism from a historical perspective by means of qualitative, textual analysis. The aim is to display the structural and discursive changes during the second half of the 20th century and the first decade of the 21 st in the form and content of newspaper coverage of blockbusters as both cultural commodities and cultural phenomena.

More specifically, we examine the coverage of three American blockbusters: Ben-Hur (1959/1962), Batman Forever (1995), and Sex and the City (2008) in Danish printed newspapers by analyzing the use of genres, the thematic focus, and the arguments deployed to discuss and evaluate these blockbuster movies. We hypothesize that the changes exemplified by the coverage of these selected blockbusters are linked to (a) an increasing professionalization of publicity efforts on the part of the movie industry aimed at the newspapers and (b) the development of a double — publicist and commercial—contract in the cultural journalism of printed newspapers, facilitating information and debate about culture while at the same time providing the readers with entertainment and service. We argue that the interwoven communicative forms or logics of the movie industry and the press can be explained by ongoing mediatization processes: Even though the analysis shows that the press appears to be increasingly informed by the public relations (PR) efforts of the movie distributors, the changing newspaper coverage of blockbusters exemplifies the ways in which the communicative logics of cultural journalism increasingly determine the presentation and discussions of large-scale movies. Blockbusters seem to be important to the press for both media commercial and publicist reasons, and these various purposes have become increasingly apparent in the media coverage. We analyze the changing coverage of the blockbuster in the Danish printed press as an example of more general changes in the coverage of art and culture in Danish news media. The Danish media system is characterized by operating on commercial terms while at the same time being permeated by public service or publicist ideals. According to Hallin and Mancini (2004), it belongs to the Democratic Corporatist model, defined by its professional autonomy, subsidies from the state, combined with a certain degree of political parallelism, despite developments toward a more liberal model.

\section{Theory: Mediatization processes contextualizing the interplay of the movie industry and the press}

Our analyses are informed by the ongoing scholarly discussions of mediatization theory, including (a) the concept of media logic and (b) the interconnectedness or reciprocity of the media (e.g., the printed press) and other institutions in society (e.g., the movie industry).

Media logic(s) is a central but also contested concept among mediatization theorists. Inspired by Altheide and Snow (1979), Hjarvard (2008) points out that " the term 'media logic' refers to the institutional and technological modus operandi of the media, including the ways in which media distribute material and symbolic resources and operate with the help of formal and informal rules" ( $p$. 113). This approach has been criticized for being too linear and reductive (e.g., Couldry, 2008; Hepp, 2013) because it indicates sequential transformations and the existence of one all-encompassing media logic while failing to embrace the diversity and complexity of the current media landscape. Lundby (2009), for example, argues that "it is not viable to speak of an overall media logic; it is necessary to specify how various media capabilities are applied in various patterns of social interactions" (p. 117). He further argues that "[m] ediatization research should put emphasis on how social and communicative forms are developed when media are taken into use in social interaction" (Lundby, 2009). In his latest work, Hjarvard (2013) argues for the necessity of applying an approach that effectively combines practices of social interaction with the affordances of the specific media that structure these interactions. That is, specific media platforms, for example, printed newspapers are characterized by 
specific technological, material, and esthetic affordances-deadlines, genres, materiality (paper), organization of content, modality (interplay of text and image) — which may overlap with or differ from the affordances of other media platforms, for example, television, radio, news websites, tablets. Even printed newspapers exhibit varying degrees of logics in terms of deadlines, publication frequency, modes or styles of writing, layouting, and addressing of readers, and so forth. National broadsheets address a broader or different audience than local newspapers or tabloids do, and broadsheets brand themselves in different manners or adopt specific profiles by giving priority to specific kinds of content: politics, business, sports, art and culture, and so on.

However, it is not only news media that operate according to different logics; lm institutions are also characterized by different types of logics. The logic of Hollywood movie productions varies considerably from that of independent movie productions, for example. As a consequence, "mediatization effects may vary from one ( ... ) institution to another" (Schrott, 2009, p. 45) because the institutional logics on a microlevel shape the social interactions of media professionals, for example, newspaper journalists at the cultural desks, as well as social agents, for example, artists or press agents from different parts of the movie industry.

Following Lundby (2009), we focus on the ways in which the "communicative logics"-or the communicative approaches, forms, or intentions - of the (Hollywood) movie industry and (Danish) printed newspapers have accommodated each other, and the ways in which this communicative and relational interplay becomes visible in the newspaper coverage of blockbusters at different historical times. Inspired by Lundby's (2009) argumentation, we analyze the social and communicative forms ensuing from the Hollywood movie industry using the cultural pages of the printed press to promote blockbusters. But we also examine the social and communicative forms emerging in Danish printed newspapers when American blockbusters are covered, including the mutual interdependence and transformation characterizing their relationship or interaction. From a methodological/analytical perspective, we thus use the concept of communicative logics as a link between the more macrostructural processes of mediatization (changing relations between the Hollywood movie industry and the press) and our microanalytical approach to the newspapers' coverage of selected blockbusters (changing use of genre, increasing inclusion of publicity material, changing argumentation in reviews, etc.). In this way, we wish to demonstrate the influence of the communicative logic of cultural journalism on the communicative logic of the film industry in regard to the press, and vice versa.

\section{Movie publicity: The press as vehicle for blockbuster promotion and public legitimacy}

Ever since the early Hollywood star system, it has been an institutionalized practice for the film industry to publicize its movies, including blockbusters, across a wide range of print media (DeCorda, 2001; Marshall, 2006). However, since the 1970s, these efforts have become increasingly professionalized (Thompson, 2007) and have included the development of a set of publicity genres, conventions, and information subsidies (Gandy, 1982), tailored to the needs of the news media: press kits, press junkets, press screenings, press tours, "making-ofs"-material, and so on (Durie, 1993; ompson, 2007). ${ }^{1}$

The movie industry's need for professional communication has increased in proportion with the soaring production and distribution budgets brought on by the economic size and risk of the blockbuster. Blockbusters are characterized by exorbitant actor and director fees, costly state-of-the art special effects, and enormous marketing budgets (Schatz, 2003). The aim is to produce movies exceeding anything ever seen before both in terms of technology, esthetics, and revenue. Blockbusters are in fact often labeled "event films" (Neale, 2003), suggesting that they are typically pushed into, for example, 
the cultural pages of printed newspapers as part of meticulously planned marketing and publicity strategies designed to promote not only the movie itself but also a range of related cultural commodities, such as books, merchandise, and soundtracks. This is done deliberately to gradually raise public awareness and build expectations, which may either be fulfilled or shattered at the premiere.

The printed press is of course only one of many targeted media platforms and communication channels involved in blockbuster promotion. The Internet and social media have provided new avenues for hyping movies by means of both old and new communication and marketing strategies (Thompson, 2007). However, the institutionalized arrangements of press junkets, kits, screenings, tours, and so on, as well as the ever-increasing promotion budgets of the movie industry denote that publicity in mainstream news media continues to be a priority. Compared to cultural journalists' and press agents' professional and routinized genres of interaction, social media, user-generated content, and viral marketing are more unpredictable and less controllable (Thompson, 2007) and may be associated with less credibility as shown by research on user-generated content in journalism (e.g., Wahl-Jørgensen, Williams, \& Wardle, 2010). Furthermore, the primary purpose of these platforms is to provide access to specialized subpublics (Hindman, 2009), that is, websites for devoted fans and their dedicated discussions, rather than to the broader discourses of and across the (omnibus) press. ${ }^{2}$ Accordingly, newspapers continue to serve not only as a marketing window but also as a platform for public legitimacy, confirmation, and reproduction of movie blockbusters as blockbusters, that is, as newsworthy as well as important cultural phenomena.

\section{News value: Blockbusters as vehicles for profiling content and debate in cultural journalism}

Even though scholars disagree on the importance of the press as "influencers" or "predictors" (Boatwright, Basuroy, \& Kamakura, 2007; Eliashberg \& Shugan, 1997) of the commercial success/failure of movies, the continuous symbolic value of cultural critics' assessments in the newspapers is indicated by the integration of (positive) ratings in movie marketing materials such as posters, billboards, and advertisements. Moreover, the existence of a critical discourse in reviews and in cultural journalism more generally may contribute to the legitimization of especially popular cultural expressions such as the blockbuster (Baumann, 2001; Klein, 2005). However, newspapers and their cultural journalists not only perform the role of marketing tool when covering blockbusters; they also evaluate or frame blockbusters in particular ways. As the analysis will show, the point of departure for these evaluations or framings has changed considerably during the last 50 years in tune with the Danish news media developing from "cultural institutions," aiming to provide public service and educate the public, to "media institutions" (Hjarvard, 2013, p. 51) with an increased focus on their own commercial interests and cultural profiles (Kristensen, 2010). Blockbusters as a topic in cultural journalism carry great news and cultural value by representing issues of great interest to the newspaper readers; this explains the dual publicist and media commercial reasons for covering them. The already mentioned gigantic production costs and long-term marketing efforts make blockbusters inevitable not only in the public debate but also on the agenda of the newspapers' cultural pages. These production and marketing budgets also heighten expectations and thus the potential for either spectacular success or abject failure at the opening, "delight or disappointment" (Stringer, 2003, p. 7), both of which are newsworthy from the perspective of cultural journalism. That is, from a publicist perspective, the blockbuster may spark essential discussions about esthetics, the distinctions and interplay between art and popular culture, cultural-industrial circuits and commercial issues, and so forth. Another important characteristic of the blockbuster is this very negotiation of its cultural or artistic value (Stringer, 2003, p. 8) that for years has contextualized it as cultural phenomenon. First of all, the term "blockbuster" unites quite dissimilar movies, characterized by some of the same production values all closely 
associated with "magnitude."3 Second, because of the enormous industrial apparatus that sustains blockbusters, they are most often associated with commercial motivations rather than artistic ones, despite the technical innovations they often foster. Third, in contemporary convergence culture (Jenkins, 2006), this commercial discourse, as mentioned earlier, is emphasized by the commercial circuit that blockbusters are often an inseparable part of; that is, the cultural commodities (merchandise, bestsellers, television series, computer games, music, celebrities, etc.) that they promote or are themselves spin-offs of (Schatz, 2003), and that make them part of transmedia storytelling (Jenkins, 2006, p. 97) or franchise adventures (Thompson, 2007). The fact that the blockbuster touches such a wide variety of cultural fields means that newspapers, as both cultural institutions and media institutions, are not only expected or compelled to discuss these global phenomena from various perspectives but also have an interest in doing so.

These discussions exemplify the increasing mutual dependency and reciprocity of the movie industry and the press; they exemplify the processes of mediatization. From a media critical perspective, these changing patterns of social interaction are often associated with declining resources in journalism and subsequently increasing demands for content as part of the escalating competition in the news industry (e.g., Strahan, 2010; Thompson, 2007). One may also, however, associate the changing patterns with increasing competition for media visibility among cultural producers (e.g., Hjarvard, 2013, p. 63) as the focus, interpretation, and presentation of cultural topics change and expand in cultural journalism in line with a changing cultural concept and a professionalized media landscape (Kristensen \& From, 2011). This increasing competition for media visibility or media exposure is further emphasized by the escalating production budgets in Hollywood. In the following, we explore, from an empirical-analytical perspective, the ways in which these changing patterns of social interaction can be observed in the specific products or texts of cultural journalism: the journalistic coverage of blockbusters.

\section{Methodology 4}

The empirical point of departure for the following analysis is the coverage of American blockbusters in Danish newspapers during the 20th and first part of the 21st centuries. In addition to disagreeing on what exactly constitutes a blockbuster, scholars have also yet to agree on when the blockbuster was "conceptualized." However, what they do agree on is that it is an American post-World War II phenomenon (e.g., Neale, 2003; Schatz, 2003). That is, an epoch closely connected with a professionalization of the movie industry's PR efforts and a broadening cultural concept characterized by dissolving boundaries between highbrow and lowbrow. For that reason, we have chosen to look at the coverage of American blockbusters since the middle of the 20th century.

The analysis includes articles covering three specific blockbusters in selected Danish national newspapers: The center-right, business-oriented broadsheet Jyllands-Posten; the center-left, culturally oriented broadsheet Politiken; the tabloid Ekstra Bladet; and in 2008, the free newspaper MetroXpress. The articles were accessed by means of (a) micro lm; (b) Infomedia, an online-provider of access to the content of a range of Danish news media; and (c) archival clippings preserved by the Danish Film Institute.

The three movies are Ben-Hur (1959), the remake of a silent movie from 1925, adapted from the novel Ben-Hur: A Tale of the Christ by Wallace Lew, which opened in Denmark in 1962, and which has repeatedly been labeled a blockbuster (e.g., Stringer, 2003); Batman Forever (1995), based on the DC comics character Batman; and Sex and the City (2008), the movie spin-off of the internationally successful television series with the same title and also considered a blockbuster at the time of its 
release. $^{5}$ This sample of movies may appear somewhat arbitrary, but they were selected on the basis of a quantitative, longitudinal study of the changing coverage of art, culture, and lifestyle in the Danish press during the 20th and first decade of the 21st centuries (Kristensen, 2010; Kristensen \& From, 2011). The study presented in this article is thus a qualitative continuation of an existing quantitative study. Accordingly, the analyzed movies were not selected because of their specific esthetic, narrative, or technological similarities or differences nor their success at the box office. They were selected as typical, albeit perhaps dissimilar, examples of the press coverage of blockbusters at the given time: the 1960s, 1990s, and 2000s, which were decades examined in the preceding longitudinal study. The chosen movies do, however, illustrate the wide "generic" framework of what may be considered a blockbuster, just as they are all part of a cultural circuit, which includes adaptations or spin-offs from literary, film, and/or television originals.

The analysis explores the use of genres, the thematic focus as well as the arguments deployed to report and evaluate the blockbusters, and the ways in which this reporting and film critical argumentation have changed significantly during the 50-year time period, which the selected movies and their press coverage represent.

\section{Analysis 6}

The following analysis aims to display, first, the increasing — and increasingly successfulprofessionalization of the movie industry's adaptation to the needs and logics of cultural newspaper journalists, as evidenced by the latter's increasing use of publicity information. Second, the analysis intends to demonstrate the increasingly multifaceted coverage of blockbusters, involving a spectrum from critical debate to pleasurable entertainment, revealing the double contract of contemporary cultural journalism.

\section{Intensified and increasingly varied press coverage}

The Danish press coverage of Ben-Hur lasted several years: The newspapers preannounced Ben-Hur during its making in 1958, prior to its American and European opening in 1959, when it won 11 Academy Awards in 1960, and before its Danish premiere in 1962. This long but also relatively scattered coverage typically focused on the extraordinary production process, providing factual information about the size of the production and expectations of director William Wyler. The coverage also contextualized the upcoming movie within an already established cultural circuit by making reference to the novel the movie was based on and the silent-movie version from 1925 . However, the media coverage included no production or celebrity interviews with the movie's star director (William Wyler) or actor (Charlton Heston). The opening in Danish cinemas 19 February 1962 instigated mainly reviews, typically published 1 or 2 days after the opening, denoting that no press screenings had been organized prior to the opening; the reviews thus provided no service information about the movie (e.g., where and when to watch it). Despite the prolonged coverage, the reporting and media discussion of one of the most spectacular productions in film history therefore seem relatively limited and dispersed even to this day. This may be a result of deliberate editorial decisions, indicating that this kind of movie was not given high priority despite its broad audience appeal. Danish as well as other European intellectuals were generally quite critical at the time of the American influence on, or the Americanization of, national culture and society after World War II (Petersen \& Sørensen, 2006); they were particularly critical of the influence from American popular culture. The limited coverage may, however, also reflect the fact that the main role of film industry PR at the time was to provide factual information about the movie production and its cast, thus indicating that the journalists had access to some PR information, but that a broader generic palette of professional communication conventions 
had not yet been developed. 7

The opening of Batman Forever in Denmark 4 August 1995, a month and a half after the American opening, prompted a much more extensive coverage, including a more varied use of genres compared to the opening of Ben-Hur approximately 30 years earlier. This confirms the conclusion by several longitudinal studies of cultural journalism in different Western countries, Denmark, among others (Janssen, Kuipers, \& Verboord, 2008; Knapskog \& Larsen, 2008; Kristensen, 2010), which show that the coverage of culture, including movies, has increased considerably during the past decades. In continuation of Janssen et al. (2008), this may be explained by the development of a global movie industry and a more international orientation within the press in general. It may also, however, be a consequence of the simultaneously expanding celebrity culture, facilitated by the increasingly competitive and globalized media industry. Celebrity scholars, for example, argue that celebrities have increasingly become a media-made and media-sustained phenomenon during the second half of the 20th century (e.g., Turner, 2010). In a Danish context, this is again confirmed by longitudinal studies of the printed press, which demonstrate that even though celebrity journalism increased with the introduction of talking pictures and popular music genres back in the 1930s, it expanded even further in the last decades of the 20th century (Kristensen \& From, 2011, p. 138). Accordingly, the preannouncing articles on Batman Forever featured celebrity portraits of Drew Barrymore, playing Sugar, revealing details about her turbulent private life (Ekstra Bladet, 11 June 1995) as well as interviews with upcoming star Chris O’Donnell, playing Robin (Ekstra Bladet, 13 April 1995), and actor Val Kilmer, starring as Batman, who had already reached superstardom (Politiken, 31 July 1995). These articles were, among other things, based on input from professionally organized press junkets, indicating that the movie industry and cultural journalism had by then adopted more routinized or professionalized practices for producing, sharing, and using PR material. Furthermore, the tabloid Ekstra Bladet published red-carpet reportages from the American opening, again emphasizing its star and celebrity qualities (Ekstra Bladet, 11 June 1995). This highlights the interwoven and increasingly complex circuit of interest and logics that governs movie producers, cultural journalists, and celebrities, and thus the entire movie industry, the media industry (in this case, the printed press), and celebrity culture.

This professionalized interplay had become even more profound when Sex and the City opened 6 June 2008, in Danish cinemas, a few weeks after its world premiere in England. This was evident in the framing of the opening as a large-scale "pseudo event" (Boorstin, 1961). Under the headline "Hot Women in the Lobby and on the Screen," the broadsheet Jyllands-Posten (2 June 2008) advertised the premier in the second-largest Danish city, Aarhus, where 600 specially invited women watched the movie while drinking cocktails in their finest outfits and highest stilettos, thus imitating the lifestyle of the female movie characters. Five days later, Jyllands-Posten reported from the Aarhus-opening in an on-the-spot reportage: "This evening New York has moved to the Jutland capital" (Westersø, 7 June 2008, p. 11), alluding to the branding of the movie not only as a cultural product with distinctive esthetic and narrative traits but also as a diffusion of specific kinds of lifestyles, reaffirming the characters' way of life within as well as outside the fictional universe. The preannouncing coverage also included more traditional interviews with the leading actresses as well as articles pinpointing important Sex-and-the-City-Manhattan-spots, again emphasizing the reciprocity of Hollywood, news media, celebrity culture, and experience economy more broadly.

The more diverse coverage of the opening of Batman Forever and Sex and the City compared to BenHur indicates that interview sessions and marketing information about the two more recent releases had been pushed into the press circuit by the movie industry, and that the press had actively exploited this information access. This confirms that PR subsidies were becoming increasingly more "structurally 
embedded in" (Strahan, 2010, p. 128) or a normalized (Marshall, 2006) part of cultural journalism during the second half of the 20th century.

\section{Box office expectations and horse races - the economic fascination of blockbusters}

The analysis also reveals an increasing focus on blockbuster budgets and box office revenues in Danish newspapers during the second half of the 20th century. This exemplifies the upcoming of what Thompson (2007, p. 112) has labeled "horse race-coverage" of movies. This refers to the news coverage of (opening) weekend box office results and is yet another example of the increasing professionalization of the movie industries' press relations. 8

When the Danish press covered and reviewed Ben-Hur during its production and at its subsequent premieres (1958-1962), its production budget was, as indicated, often touched upon. The reviewers all agreed that the movie had its spectacular moments. This is exemplified by the headline of the review in the tabloid Ekstra Bladet (20 February 1962), "The nine most exiting minutes," which explicitly addressed the movie's spectacular chariot race sequence, arguing that these 9 minutes might even justify the movie's enormous production budget. The newspapers also followed up on its revenues. For example, the broadsheet Politiken announced in a headline 2 years after the Danish opening, "BEN HUR is catching up on "Gone with the Wind"' (9 January 1964).

In the case of Batman Forever, the Danish press coverage included several news articles on box office expectations for the upcoming movie, highlighting the movie plot as more child-friendly compared to that of its predecessors because of its brand partnership (Thompson, 2007) with McDonald's in the United States (e.g., Ekstra Bladet, 5 May 1995; "Child-Friendly Batman"; Politiken, 15 May 1995, "Batman and the Hamburgers"). These headlines indicate the cultural journalists' analytical attention to the commercial ties and interplays in large-scale movie productions, which provide specific frameworks for esthetic and narrative creativity but also stir up an implicit critical gaze in the news media. Furthermore, the newspapers published notes, phrased almost identically, on the box office revenues after the American opening weekend. These notes all framed the movie as a great commercial success, thus implying that the newspapers had used or reproduced the same information subsidies (e.g., Politiken, 20 June 1995, "Batman Breaks the Record”; Politiken, 2 July 1995, "New Movie Records in the USA"; Ekstra Bladet, 11 June 1995, "Circus Batman"). In fact, many articles focused more on the industrial production and opening aspects than on esthetic or narrative features, epitomized by this quote from the tabloid Ekstra Bladet (Gregers, 12 May 1995, p. 25): "The expenses for this summer's big-hit movie has increased so enormously that even hardened movie producers now worriedly frown and question the sanity of producing movies that cost 70, 80, 90, even more than 100 million dollars." This implies that the economic framing is not univocally uncritical because the newspaper implicitly questions the large-scale production values (and risks) associated with the blockbuster.

The coverage of Sex and the City also addressed the financial aspects of this movie, reporting briefly that the American premiere had been twice as successful as expected and more lucrative than any other romantic comedy (Jyllands-Posten, 4 June 2008). Furthermore, the newspapers framed Sex and the City as a spin-off of the very successful television series of the same title, covering the opening as part of a large cultural and industrial circuit, characterized by blurring boundaries between lifestyle, cultural products, and commercial interests. Under the headline "Superbowl for Women," the business section of the (financially oriented) broadsheet Jyllands-Posten, for example, debated the movie on its opening-day (6 June 2008), not as an esthetic expression or as a star-driven movie about sex and celebrities but as a vehicle for cobranding commodities such as fashion trends and products (shoes, 
clothing, food products, etc.), and, more importantly, ways of life (Kristensen \& From, 2011), arguing that the movie produces stylistic icons. Thus, the newspapers addressed product placement as a principal part of the fictional construct, and lifestyle products as an important part of the movie's attraction, whereas the technological aspects were given more attention in the case of Ben-Hur and Batman Forever. This again alludes to the increasing reciprocity not only of the film industry and the news media but also of the film industry, the media, and producers of lifestyle brands and commodities. Even though parts of the coverage of Sex and the City addressed the fact that too much product

placement might distract the narrative, ${ }^{9}$ this focus on movie-external features exemplifies that cultural journalism by then was incapable of merely reviewing, criticizing, or evaluating a blockbuster such as Sex and the City as a narrative or esthetic artifact; it had to also be analyzed and contextualized within its complex consumer and media cultural and commercial context.

It is therefore clear that printed newspapers have focused increasingly on the economic side of the blockbuster ever since Ben-Hur, typically paying positive attention to its large-scale production values (stars, budgets, box office, and technology) and adopting the commercial rhetoric of the movie industry in the process. This reveals an increasing fascination with the movie industry as well as an awareness of the risks associated with these mammoth productions. But the shift in focus is also indicative of the news media's increasing awareness of and preoccupation with coproduction and brand-corporation as an institutionalized part of movie production and distribution by the end of the 2000s.

\section{The double contract: Public debate recognizing the reader as both cultural citizen and cultural consumer}

The analytical arguments presented above may be said to confirm the very critical voices that have condemned cultural journalists for running the errands of the cultural industry. However, as this section will reveal, the coverage of all three movies also exemplifies newspapers that facilitate public debate and reflection on film culture as well as take their point of departure in dissimilar premises and approaches, closely connected with the cultural, media institutional, and societal circumstances of their time.

Even though the Danish press coverage of Ben-Hur appears relatively limited compared to the coverage of Batman Forever and Sex and the City, reviewers and the public anticipated this movie. The review in Jyllands-Posten, "Rome Before and Now and an Exhausting Ben-Hur" (Monty, 22 February 1962, p. 22), for example, repeated the preannouncing framing of Ben-Hur as a spectacular "phenomenon": "Finally the huge movie is launched in Denmark. Unfortunately, it was not worth waiting for." This explicitly exemplifies the high expectations typically associated with blockbusters and their often polarized receptions among film critics and/or audiences. Even though Ben-Hur was recognized as a topic of interest to the readers, it was evaluated on the basis of art rather than popular or mainstream culture. Jyllands-Posten argued that "Wyler has at no point put his personal mark on the movie - 50 other Hollywood craftsmen could have done the same" (Monty, 22 February 1962, p. 22). Similarly, Politiken explicitly placed Ben-Hur in opposition to art, "Here the now former artist William Wyler celebrates his triumph number one as producer of mass entertainment" and "This is all quantity-but not art" (Engberg, 20 February 1962). The rhetorical framing of the reviews with a strong focus on art thus implies that popular movie genres were (often) seen as being of low quality and symptomatic of the Americanization of the film industry of the time. This is confirmed by the coverage in Danish newspapers of the Academy Awards won by Ben-Hur in 1960, appraising a French actress for outcompeting her American contestants but sidestepping Ben-Hur's historical achievement at the Oscars. ${ }^{10}$ In other words, the coverage presented a rather skeptical position, framing the evaluation of 
"good" versus "bad" as closely related to art and judging Ben-Hur as a movie of poor quality by implying that audiences actually enjoying the movie were insane: "If you, after having consumed this picture novel, are still hungry for more 'Ben Hur', for more entertainment, you ought to be hospitalized" (Engberg, 20 February 1962). Notwithstanding this discursive determination of the American blockbuster as a film category of less cultural value, the various quotes suggest that BenHur - as a large-scale movie - did after all foster critical debate on movies as a cultural phenomenon and artifact.

As mentioned above, the coverage of Batman Forever raised a more varied debate and use of genres. Even though the interview-based articles all framed the movie as star- or celebrity-driven, the newspapers adopted quite diverse approaches. In Ekstra Bladet, the interviews dived into the private lives of the stars, as is typical of the tabloid press, while Politiken displayed an (implicit) ironic distance in regard to the stars and the media circus following the movie release and the blockbuster as a phenomenon. In the article "Batman Flies Again," Politiken, for example, reported from a press junket at which the lead actors and the director, Joel Schumacher, were present:

Even without introduction, one had probably guessed that it was him [Eds. Val Kilmer], especially considering the entourage of assistants always eagerly and very, very seriously surrounding Hollywood-stars as if they were members of the royal family or politicians on an important mission. (Hellmann, 31 July 1995, p. 1)

Rather than simply play along with the press circus instigated by the blockbuster movie, the journalist uses the opportunity to make an implicit critical comment on the institutionalization of the mutual dependency of the movie and media industry, as exemplified by this professionalized staging of the interaction of journalists and (celebrity) artists. In other articles (e.g., "The Scoundrels of Batman," 29 July 1995), Politiken analyzed the cross-media development of the characters of the Batman universe, that is, how the characters evolved across time and media platforms - from the original DC cartoons from 1939, to the television series from the 1960s and the Batman-movies of the 1990s, taking seriously the fantasy universe and its characters and placing them within a historical context. The media institutional differences indicated by these preannouncing articles, that is, the celebrity approach of the tabloid newspaper and the more distanced and analytical approach of Politiken, are confirmed by the very dissimilar approaches and claims they deployed when reviewing the movie. Ekstra Bladet categorized Batman Forever as a good movie, arguing that "The movie is excellently made" (Kodal, 4 August 1995, p. 21). The tabloid also emphasized the production and use of technology as fascinating and worthwhile, thus implying that technological innovation had become a quality parameter. In contrast to this positive approach, Politiken ranked Batman Forever as a bad movie: "The inventiveness is not huge" and "you cannot experience it as art for the sake of art" (Mohn, 4 August 1995 , p. 5). The paper thus argued that art was still a relevant yardstick for evaluation, regardless of Batman Forever being an action-adventure blockbuster movie. In a broader media institutional perspective, these differences between newspaper opinions exemplify that cultural journalism-and opinionated genres such as the review in particular - may differentiate, profile, or segment the individual newspapers (Kristensen \& From, 2011), similarly to their political leanings (Hjarvard, 2010). That is, the differences are indicative of a transformation that fuses the branding of the newspapers and the framing of cultural journalism and cultural criticism.

Also the coverage of Sex and the City demonstrates the newspapers' use of the blockbuster as platform for accentuating specific cultural profiles. The tabloid Ekstra Bladet and the free newspaper MetroXpress, for example, published many gossip articles about and interviews with the lead actresses (e.g., Ekstra Bladet, 22 June 2008; MetroXpress, 3 June 2008); and Ekstra Bladet, echoing the tabloid 
magazine press, ranked the outfits worn by Danish female celebrities (including the Danish prime minister) at the movie opening in Copenhagen (8 June 2008). The tabloid also used the opening as an occasion to debate the sexual appeal of the movie (7 June 2008, "They teach us how to fuck"), based on an interview with a sex therapist (and national "celebrity"). Besides alluding to the already mentioned obvious relations between the movie industry and consumer culture, these articles exemplify how the tabloid contextualizes the coverage of the movie within a broader everyday life and "newsyou-can-use" context (Kristensen \& From, 2011; Underwood, 2001) instead of simply addressing its esthetic, narrative, or industrial aspects. In agreement with its more academic or intellectual profile, the broadsheet Politiken applied an analytical approach by explaining (some) women's fascination with romantic comedies like Sex and the City from a biological perspective based on an interview with a Danish film scholar (17 July 2008, "Romantic movies can be instructive"). Again, this exemplifies the way in which cultural journalism may contextualize the interplay of cultural consumers and cultural products and in this manner negotiate cultural values by providing new frames for understanding and evaluating popular culture. Moreover, the coverage of Sex and the City indicates that generic aspects were an important part of the argumentation, especially in the reviews, evaluating the movie in the light of expectations associated with the romantic comedy as genre. Politiken, for example, stated that "The most important ingredients are still part of the universe in the movie version ( ... ) the dose, however, has been changed so radically that - unfortunately - there is less sex, less city, and less humor" (Jensen, 6 June 2008, p. 4). This indicates that the newspaper neither compared Sex and the City to fine art nor discussed it as trash or low culture; it was compared to movies of the same genre and, of particular importance, to the extremely popular television series from the early 2000s, on which it was based. Accordingly, the coverage kept creating links to the broader cultural and industrial circuit, which the movie was a part of, being a spin-off cultural commodity, that is, a cultural phenomenon or trend touching upon gender issues, sex, fashion, salaries, big city life, and so on. For the same reason, Sex and the City was often used as a cultural reference in newspaper articles covering a range of topics. Politiken, for example, published the opinion piece "Women Ready for Power, "Sex and the City" (26 July 2008) on the increasing sex segregation of Danish society. The article juxtaposed well-educated, adaptable women echoing the female lifestyle of Sex and the City with men seeking confirmation in fraternities "for guys only." The piece did not touch upon Sex and the City as a cultural artifact but included the views of sexually liberated women expressed through its fictional universe as a cultural and social framework. Thus, at the opening of the movie, the audience's - and the reviewers' expectations were shaped by encounters with the existing television series as well as by the ongoing societal debates on gender, family, and ways of life, which Sex and the City was part of. But their expectations were also influenced by the marketing material distributed during the production of the movie. It is therefore hardly surprising that almost all reviews and articles compared the characteristics of the series and the movie, thus proving that contemporary blockbusters form part of a vast circuit of interconnected popular genres and cultural forms with blurring boundaries between texts, cultural expressions, and society.

Even though Ben-Hur and Batman Forever were also adaptations of other cultural expressions, this legacy was less explicit in both cases. At the turn of the 21 st century, however, the opening of a blockbuster is a more inevitable event than ever before from a cultural journalistic perspective. This is primarily because of the rapidly changing and omnipresent cross-media environment and production culture, but it is also because the blockbuster may be seen as an opportunity to address and discuss a range of social and cultural issues on the cultural pages of the newspapers.

\section{Conclusion}

The analysis presented in this article shows, first, that during the analyzed 50-year period, the Danish 
press covers blockbuster movies from an increasing number of angles and by means of an increasing variety of genres. While the review remains a consistently recurring genre, other genres, such as preannouncements of upcoming blockbusters, short updates on box offices grosses, premiere and celebrity interviews with and portraits of directors and actors, the launching of spin-off commodities, now occupy more and more columns' space. However, the press also increasingly sees the opening of a blockbuster as an opportunity to address these kinds of movies in more analytical articles, discussing the blockbuster as a globalized film cultural but also sociocultural phenomenon. Second, the analysis demonstrates the movie industry's changing opening patterns and that the press has adapted its coverage accordingly. In the case of Ben-Hur, the international opening lasted several years, resulting in a scattered newspaper coverage. In contrast, the opening of Batman Forever, and especially Sex and the City, represents global (media) events taking place almost simultaneously worldwide, thus resulting in intense media coverage for shorter periods of time. Third, the analysis shows that the negotiation and definition of the blockbuster as a phenomenon has changed in the press. While it used to be critically interpreted as a sign of cultural imperialism, Americanization, or artistic decline, it is increasingly viewed as a global, omnipresent, cultural and industrial phenomenon with its own esthetic, narrative logic and worth, but also with its own social and broader cultural worth. This indicates that when covering blockbusters, contemporary cultural journalists address the readers as both "social" and "cultural" citizens (Syvertsen, 2004) by alluding to the conditions of modern life as they are expressed through the fictional constructs.

These changes reflect the increasing professionalization of the interplay between the Hollywood industry and the press and between the competing news media and their logics, suggested by the increasing awareness of genre, attention to reader segments, and a broadened and less hierarchical interpretation of culture. The coverage thus exemplifies that the blockbuster has been and continues to be negotiated as a (relevant) topic in cultural journalism; that cultural journalism provides different reflective spaces for popular culture at different times; and that contemporary cultural journalism continues to be critical and contemplative while at the same time providing cultural service and infotainment.

From a more overall perspective, the changing coverage of blockbusters exemplifies the mediatization of cultural products and phenomena and, more specifically, the three functions served by the media in contemporary society, according to Hjarvard (2013). First, the newspapers serve as an interface between the movie industry and cultural consumers, constituting a resource for both industrial interests and the cultural public. This is rooted in the double contract of cultural journalism, facilitating both commercial and publicist purposes. The many preannouncing articles on and reviews of Ben-Hur, Batman Forever, and Sex and the City focused, critically or positively, on the large-scale production values of these movies (stars, budget, box office, technology, cobranding, etc.) and thus on the movies as commercial products, cultural artifacts, and phenomena of their time. That is, the movies were viewed as being part of a commercial as well as a cultural circuit. The newspapers also serve as providers of a realm of shared experience, for example, by debating and creating awareness about global cultural phenomena such as the blockbuster. All three blockbusters were cultural experiences that "everybody had been waiting for"; they represented a shared point of reference partly because of their coverage and public discussion in national newspapers. Finally, the media represent a cultural public sphere by providing a forum for cultural legitimization; it is a sphere in which Hollywood, in this case, can negotiate and defend their production values and establish legitimacy.

\section{Notes}

1 These developments echo transformations within a range of other societal fields, for example, 
political communication and corporate communication.

2 In spite of an increasing segmentation of the individual newspapers (Hjarvard, 2013), Danish newspapers continue to be important political and cultural agenda-setters. They reach larger parts of the public, and they are important to the public's conception of how they are informed about cultural products and events (Kristensen \& From, 2011).

3 We deliberately do not discuss whether or not the blockbuster is a genre.

4 The empirical data has also been used in Kristensen and From (2013) to exemplify how cultural journalists have redefined their role as "cultural intermediaries" (Bourdieu, 1984).

5 http://articles.latimes.com/2008/jun/02/business/-boxo ce2/ (last retrieved 7 October 2013).

6 All quotes have been translated from Danish by the authors.

7 Archival clippings, preserved by the Danish Film Institute, including original PR material, show that PR material was distributed to the press prior to the opening.

8 Traditionally, "horse-race journalism" refers to political journalism during election campaigns, when journalists cover the campaign as a horse race between candidates, including constant public poll updates (e.g., Littlewood, 1998).

9 The reviewer in MetroXpress, for example, argued: "The considerable fascination of brands is so intense and exaggerated throughout the 148 minutes that you almost drown in product placement" (Langelund, 2008, p. 46).

10 Only Titanic (1997) and Lord of the Rings: The Return of the King (2003) were awarded a matching number of Academy Awards.

\section{References}

Altheide, D., \& Snow, R. P. (1979). Media logic. Beverly Hills, CA: SAGE.

Baumann, S. (2001). Intellectualization and art world development: Film in the United States. American Sociological Review, 66(3), 404-426.

Boatwright, P., Basuroy, S., \& Kamakura, W. (2007). Reviewing the reviewers: the impact of individual film critics on box offce performance. Quantitative Marketing and Economics, 5, 401-425.

Boorstin, D. (1961). The image: A guide to pseudo-events in America. New York, NY: Harper Colophon.

Bourdieu, P. (1984). Distinction: A social critique of the judgement of taste. London, England: Routledge.

Couldry, N. (2008). Mediatization or mediation? Alternative understandings of the emergent space of digital storytelling. New Media \& Society, 10(3), 373-391. 
DeCorda, R. (2001). Picture personalities: e emergence of the star system in America. Urbana: University of Illinois Press.

Durie, J. (1993). The film marketing handbook. Madrid, Spain: Media Business School.

Eliashberg, J., \& Shugan, S. M. (1997). Film critics: Influencers or predictors? Journal of Marketing, 61(2), 68-78.

Engberg, H. (1962, February 20). De ti bud - budt over [The ten commandments - overbid].

Politiken.

Gandy, O. (1982). Beyond agenda-setting: Information subsidies and public policy. New York, NY: Ablex.

Gregers, A. (1995, May 12). Sommer med superfilm [Summer with super-movies]. Ekstra Bladet, p. 25.

Gripsrud, J. (2000). Tabloidization, popular journalism, and democracy. In C. Sparks \& J. Tulloch (Eds.), Tabloid tales: Global debates over media standards (pp. 285-300). Lanham, MD: Rowman and Little Field.

Hallin, D. C., \& Mancini, P. (2004). Comparing media systems. Cambridge, England: Cambridge University Press.

Hellmann, H. (1995, July 31). Batman flyver igen [Batman flies again]. Politken, p. 1.

Hepp, A. (2013). Cultures of mediatization. Cambridge, England: Polity.

Hindman, M. (2009). The myth of digital democracy. Princeton, NJ: Princeton University Press.

Hjarvard, S. (2008). The mediatization of society: A theory of the media as agents of social and cultural change. Nordicom Review, 29(2), 105-134.

Hjarvard, S. (2010). The views of the news: the role of political newspapers in a changing media landscape. Northern Lights, 8, 25-48.

Hjarvard, S. (2013). The mediatization of culture and society. London, England: Routledge.

Janssen, S., Kuipers, G., \& Verboord, M. (2008). Cultural globalization and arts journalism: the international orientation of arts and culture coverage in Dutch, French, German, and U.S. newspapers, 1955 to 2005. American Sociological Review, 73(5), 719-740.

Jenkins, H. (2006). Convergence culture: Where old and new media collide. New York: New York University Press.

Jensen, E. (2008, June 6). De får for lidt [They don't get enough]. Politiken, p. 4.

Klein, B. (2005). Dancing about architecture: Popular music criticism and the negotiation of authority. Popular Communication, 3(1), 1-20. 
Knapskog, K. A., \& Larsen, L. O. (Eds.) (2008). Kulturjournalistikk. Oslo, Norway: Scandinavian Academic Press.

Kodal, J. (1995, August 2). Bedre end rutsjebanen [Better than the roller coaster]. Ekstra Bladet, p. 21.

Kristensen, N. N. (2010). The historical transformation of cultural journalism. Northern Lights, 8, 6992.

Kristensen, N. N., \& From, U. (2011). Kulturjournalistik. Journalistik om kultur. Frederiksberg, Denmark: Samfundslitteratur.

Kristensen, N. N., \& From, U. (2013). Blockbusters as vehicles for cultural debate in cultural journalism. Academic Quarter, 7, 51-65.

Langelund, S. (2008, June 6). All shoes, no sex (in the city). MetroXpress, p. 46.

Littlewood, T. B. (1998). Calling elections: the history of horse-race journalism. Notre Dame, IN: University of Notre Dame Press.

Lund, C. W. (2005). Kritikk og kommers: Kulturdekningen i skandinavisk dagspresse. Oslo, Norway: Universitetsforlaget.

Lundby, K. (2009). Media Logic: Looking for social interaction. In K. Lundby (Ed.), Mediatization: Concept, changes, consequences (pp. 101-119). New York, NY: Peter Lang.

Marshall, P. D. (2006). Initimately intertwined in the most public way: Celebrity and journalism. In P. D. Marshall (Ed.), The celebrity culture reader (pp. 315-323). New York, NY: Routledge.

Mohn, B. (1995, August 4). Batman som billeddigt [Batman as visual poem]. Politiken, p. 5.

Monty, I. (1962, February 22). Rom før og nu samt en anstrengende Ben Hur [Rome before and now and an exhausting Ben-Hur]. Jyllands-Posten, p. 22.

Neale, S. (2003). The Hollywood blockbuster: Historical dimensions. In J. Stringer (Ed.), Movie blockbusters (pp. 47-60). London, England: Routledge.

Petersen, K., \& Sørensen, N. A. (2006). Ameri-Danes and pro-American anti-Americans: Cultural Americanization and anti-Americanization in Denmark after 1945. In A. Stephan (Ed.), The Americanization of Europe: Culture, diplomacy, and anti-Americanism after 1945 (pp. 115-146). New York, NY: Bergham Books.

Schatz, T. (2003). The new Hollywood. In J. Stringer (Ed.), Movie blockbusters (pp. 15-44). London, England: Routledge.

Schrott, A. (2009). Dimensions: Catch-all label or technical term. In K. Lundby (Ed.), Mediatization: Concept, changes, consequences (pp. 41-61). New York, NY: Peter Lang.

Strahan, L. (2010). Sources of arts journalism: Who's writing the arts pages? In B. Franklin \& M. 
Carlson (Eds.), Journalists, sources, and credibility (pp. 127-136). London, England: Routledge.

Stringer, J. (Ed.) (2003). Movie blockbusters. London: Routledge.

Syvertsen, T. (2004). Citizens, audiences, customers and players. European Journal of Cultural Studies, 7(3), 363-380.

Thompson, K. (2007). The Frodo franchise: e Lord of the Rings and modern Hollywood. Oakland: University of California Press.

Turner, G. (2010). Ordinary people and the media: The demotic turn. Los Angeles, CA: SAGE.

Underwood, D. (2001). Reporting and the push for market-oriented journalism: Media organizations as businesses. In L. Bennett \& R. Entman (Eds.), Mediated politics (pp. 99-116). Cambridge, England: Cambridge University Press.

Wahl-Jørgensen, K., Williams, A., \& Wardle, C. (2010). Audience views on user-generated content. Northern Lights, 8, 177-194.

Westers $\varnothing$, R. S. (2008, June 7). Sex and the Aarhus. Jyllands-Posten, p. 11. 